\title{
The Factors Affecting Couples' Age Difference Between Two Generations of 1976 and 1986 in City of Kamyaran
}

\author{
${ }^{\mathrm{a}}$ Kazemipour, Shahlab-Qobadi, Peyman \\ a-b-Department of Social Sciences, Islamic Azad University, \\ Science and Research Branch,Tehran,Iran \\ E-mail address: s.kazmipour@gmail.com=payman_qobadi@yahoo.com
}

\begin{abstract}
Couples' age difference affects fertilizing, family planning, being satisfied with matrimony, divorce and being widow (or widower). The age difference respecting getting prepared biologically between males and females can itself cause couples'age difference. The main aim of the present study is the factors affecting couples' age difference in city of Kamyaran and contrastive comparison between two generations born in years of 1976 and 1986. The population includes 58047 of married people born in years of 1976 and 1986 (in that 26057 of which belong to the generation of 1986 and 32000 belong to the generation of 1976) in city of Kamyaran who 381 of the sampling amount were estimated based on Chochran formula in that to ignore the amount of errors, the sampling size is regarded as 400 people. The sampling method was multi-cluster one and the questionnaire was used to collect the information and they were distributed among respondents after getting approved respecting both validity and reliability. After collecting the questionnaires and reviewing them, a code was assigned for any of the questionnaires and answers and then the data were transferred into the SPSS software and the matrix of the variables got formed. To analyze the data suitable for their assessment at descriptive level, the descriptive statistics of Average, Standard Deviation (SD), Mean and tables were used and at the explanatory analysis level, Pearson Correlation, T-test, multivariable statistical techniques and graphs were also used. According to the gained results, the age difference for rural and urban males were 5.22 and 5.23 years, respectively and they were 4.26 and 3.13 for rural and urban females, respectively that age difference was more in rural females than their urban counterparts. The marriage ages for rural and urban boys are 25.28 and 25.36 years, respectively. The marriage ages for rural and urban girls are 22.4 and 22.94, respectively. The sociocultural factors, economic factors, the marriage age, masculinity and education have a meaningful relation with dependent variable.
\end{abstract}

Keywords: Couples' age difference, marriage age, masculinity, gender equity, generation, sociocultural factors

\section{Introduction}

Demographers assume marriage as one of the eminent and effective phenomena in life on main population life, especially fertilizing. Today, due to the changes in methods, viewpoints and life styles, the marriage has also changed and considering the importance of these changes has also been doubled. In this studies, increment of marriage age and choosing spouse freely based on the pattern of a great amount of social-structural changes such as increasing of education level, civilization, making new roles for females and their financial independence, growth of world- 
westernized ideas and modernity of economy, sexual acts before formal marriage, forms of marriage, choices conditions and elevation of individual choices and time of marriage are verified (AbassiShwasi and Khani, 2008). Marriage is the situation that a never-married person gets married and those who due to spouses' death become widow or widower after their marriage; they are taken for granted as married people (Zanjani, 2010). The couples' age difference underlies due to a set of factors. The marriage is often regarded as a matter related to the population, affecting the fertilizing and birth a lot. Most of the marriages are taken place because of the emotional, spiritual, mental, sexual and birth incentives as well as forming a family. Studies show that age difference between spouses vary in different places that the most important reasons are factors such as the economical ones and renewing procedure and the variables indicating them are civilization, the literacy (education) level, illiteracy, poverty, job, sociocultural factors and masculinity. Considering the physical puberty age between girls and boys and their marriage age difference, it is natural that there is difference between spouses age but their difference is not stable in all societies and even in a society. In our country, Iran for example, this difference has reduced to half, that is to three years, from 6.6 years in census of 1966 to the one done in 2006 (Iran Statistic Center, 2006). Therefore, changing the age difference is a non-biological thing and the social, population and economic changes during last 50 years in Iranian society can alter the marriage and age difference between spouses because of the matters such as getting the importance of traditions value cut and preaching new values, individualism and novelty in society and thereby, appearance of new forms of social values respecting forming family. In the era we live, the meaning of choosing a spouse and marriage faces basic changes and revolutions in comparison to the past. Having marriage postponed and besides, growth of families without or one child and new forms of family lives are the stances of this change. In the study population, i.e. kamyaran, the age difference had been low between spouses because males used to marry soon especially in rural areas but in urban areas, the growth of marriage age time is noticeable and this increment is still noticeable respecting males. The basic problem is that in more than 85 percent of marriages, the age increment is high regarding males 9males marriage age is higher than females. The spouses' age difference is related to age, civilization, education, females' literacy and spouses educational achievement (in favor of males) (Mahmoudian, 2006). Scientists assume the vast age difference between spouses as a harmful factor and they are all unanimous, however, there is no agreement on not exceeding it. According to Bernard, female are mostly satisfied when they marry a man with five years more age and this is also correct for men marrying females younger than them, ranging from zero-10 years (BagherSarokhani, 2013). What is obvious is that the changes affecting marriage and family never get linear. If we are going to figure out some of the mechanisms causing changes, one should study time, places and social environments (Segalen, 1994). The number of marriages is increased due to a set of economic problems and changing attitudes. The way of choosing a spouse has faced some changes due to alerting the meaning of marriage. Now, most of the marriages are formed without parents intervening and love as well. Having marriage postponed and increased age difference (respecting males) is one of the major revolutionizing dimensions and following it, some of the population indicators such as fertilizing and divorce are influenced and reduced by it.Investigating the recorded statistics of country in term of marriage (based on personal registry's office statistics) during last five years (2004-2009) show the $23 \%$ growth for marriage and in comparison to the $35 \%$ population qualified for marriage, this is not a noticeable figure and in spite of the influence of religious beliefs and social values affecting the society of Iran, one should get concerned and analyze it (Kazemipour, 2006). Since boys and girls cannot 
choose their spouse without any acquaintance and knowledge as it was common in the past; hoping a same level of thought, value and norm in their partnership, thereby it has become a great problem in their lives regarding choosing a spouse and in some cases it is a big barrier to get marry. They know this best that being ignorant to this can make their lives fragile and finally getting divorced is the result (Kazemipour,2006). Openhymer (1988)notes that the changes made due to marriage is because of females' role in family's economy and in other hand presumes the increment of females' job holding and Woundka (1987)states that the effectiveness of growth and development of females' education and literacy besides their autonomy is one of the eminent reasons and factors affecting marriage changes.Because of the legal age difference for couples' marriage as ruling values of marriage, apparently women are mostly younger than men getting married for the first time. This difference is higher in some societies specially the traditional ones and it is lesser in societies withwomen holding better education and occupations. Iranian studies (by AbassShawazi and et al, 2009; AskariNadawshan, 2005; Mahmoudian, 2004; Kazemipour, 2004) show that because of some important factors such as general education development, especially for women and some other novel features like making the age and patterns of marriage renewed, it is being altered and based on socioeconomic changes in last decades, females marriage age has increased. Also, people are left free to decide about their future spouse and in matrimony, the gender equity is increased.Considering this that age difference can affect factors such as spouses' sexual potency, matrimony consistency, marriage satisfaction and desirable number of children, clarifying the affecting factors can be considered as important from social and population policy making view point. Increased age difference between couples cause misconception, lack of physical fitness, lack of older spouse flexibility, emerging of uncertainty and doubt, lack of being satisfied with instincts, continual imperative-like statements by the older person and hereby, getting divorced. So, according to Demographics it is important. In addition to above mentioned items, Geedsbong-Grenshyme believe that there has been a great revolution regarding persons' attitude on gender and sexual relations and today's human beings thought on kind and amount of communicating with children is so changed that they consider their private problems more and determine based on themselves, the phenomenon that most of the sociologists call it individualism extremism.Regardless of the attitudes been dominant up to now, it was being announced in last decades of twentieth century that couples should have sexual satisfaction and it ought to be a mutual one for both parties. Along with new changes, the effect of social and economic factors and cultural shortcomings on marriage is decreased and in this situation, deciding on marriage becomes a reasonable and lasting one that requires sound and knowledgeable management that is why people use marriage counselors in most of the situations on choosing a spouse and even know practicing it correlated to different examinations to be certain they will have sound children in the future in a way that this could be called the clinically process of marriage (McKarty, 2011). Having marriage postponed specially by males may bring abundant social consequence that irresponsibility and ignorance in other aspects of life, tendency to uncommon relations between girls and boys, wasting of youth and flourished time of life, badtemperedness in life resulting from lack of meeting one's needs, parents anxiety about postponing the marriage by their children, depression and sexual disorders, being addicted to narcotics and a variety of other problems are stances to be mentioned. The reason of high age difference (for men), lack of a proper job, inflation and increased amount of unemployment among men at the time of marriage, lack of suitable university in Kamyaran and costly amount of university tuition fees in other cities universities and far distances (cultural poverty) prevents girls enter the universities and higher education and both financial and life- earning dependence 
of females on families, lack of economic dependence, lack of job, and unemployment cause early marriage of females. Females' early marriage in Kamyaran can be a factor increasing the couples age difference female economic activists have less age comparing their husbands (Mahmoudian). Job skill achievements and the necessity to have higher education degrees require passing of time and this lessens females' early marriage. Females need higher education and skills entering the market. In addition, females with job have economic autonomy and they can have more freedom and strength choosing a spouse and on the other hand, since they look for a mutual deal in marriage (Michal, 1975), they try to have the least marriage age difference marrying their husbands. Increased age difference can arise life's lack of satisfaction, lack of bearing each other, lack of understanding each other, lack of agreement, lack of flexibility as well as lack of having needs met and divorce. Couples age difference is a multivariable phenomenon and therefore, investigating marriage age difference is the most difficult section of analyzing couples age difference. Not only most of the surveys have been case studies and no one can generalize it for all, but also the factors affecting couples age have been different and even if they are common, the relative importance of them are not the same in different places.Certainly marriage plays an important role in dwellers of rural and urban lives but investigating the reasons of couples' age difference is to be taken for granted as important. Because, it is feasible to find a policy suitable for marriage age difference via a logical conception of the reasons. This study aims to find the reasons of increased age of marriage for males and the early time of marriage for females in rural areas of Kamyaran and the city itself and therefore, the general aim of the present study is to determine the factors affecting couples age in Kamyaran and investigating two generations of people born in 1976 and 1986 besides configuration of aims as well as assessing the marriage age and determining couples' age difference assessment, assessing economic situation, spouses education level, masculinity's position among respondents families, the amount of getting influence of dependent variables (spouses' age difference) by independent variables (such as economic factors, sociocultural ones, education and masculinity) have made these two generations.

\section{Methodology}

The population of the survey includes 58057 married people born in 1976 and 1985 (that 26057 of them belong to 1986 generation and 320000 belong to the 1976 one) in Kamyaran. To estimate the sample size base on Chochran formula, 381 people were counted that in order to ignore the error, the sample size was 400 . The sampling method was the multivariable cluster one and a questionnaire was used to collect the data in that they were distributed among respondents respecting validity and reliability. After gathering and reviewing the questionnaires, all of them and their responses as well were assigned an encryption and they were then transported to SPSS software and the variables matrixes were formed. To analyze the data according to their suitable assessment at a descriptive level, the descriptive statistics of Mean, Standard Deviation (SD), Median and table besides were used and at the level of explanatory analysis, Pearson Correlation, T-test, statistical Multivariable Techniques and Graphs were used. 


\section{Hypotheses test}

In this section, inferential analyses of results for the survey hypotheses are presented separately. Hypotheses: There is a significant relation between couples age difference and economic, sociocultural, education, masculinity and marriage age factors respecting generations of 1976 and 1986.

To answer the survey hypotheses to study the relation between couples' age difference and social factors, Pearson correlation test is used that the results are as follow:

Table (1): The correlation test respecting the relation between couples' age difference and economic, sociocultural, education, masculinity and marriage age for generations of 1976 and 1986

\begin{tabular}{|c|c|c|c|c|}
\hline \multirow{2}{*}{$\begin{array}{c}\text { Independent } \\
\text { Variables }\end{array}$} & \multicolumn{4}{|c|}{ Depended Variable: couples' age difference } \\
\cline { 2 - 5 } & $\begin{array}{c}\text { The severity of } \\
\text { relation }\end{array}$ & significance & number & result \\
\hline Economic Factors & -0.293 & 0.019 & 374 & Approved \\
\hline $\begin{array}{c}\text { Sociocultural } \\
\text { Factors }\end{array}$ & 0.127 & 0.011 & 400 & Approved \\
\hline Education & 0.115 & 0.022 & 400 & Approved \\
\hline Masculinity & 0.157 & 0.002 & 400 & Approved \\
\hline Marriage Age & -0.116 & 0.021 & 374 & Approved \\
\hline Generation of 1986 & 0.278 & 0,002 & 387 & Approved \\
\hline Generation of 1976 & -0.008 & 0.894 & 387 & Rejected \\
\hline
\end{tabular}

According to the above table, the approximate correlation for two variables of economic factors and age difference equal 0.293 with the significant level of 0.019 that this statistics show that there is a reverse relation between couples' age difference and social factors and the increment of one of the variables cause the reduction of another one, hereby the relation is reversed. There is a significant and positive relation between couples' age difference and sociocultural factors, that is reduction in both of which occurs simultaneously. The relation direction is positive and direct $(\mathrm{r}=0.127$; sig $=0.019)$.

There is a significant relation between couples' age difference and education and when of the variables increases, another one decreases; the relation direction is reversed and negative ( $\mathrm{sig}=0.021 ; \mathrm{r}=0.116)$.

The relation between couples' born in 1986 is significant and positive and the relations direction between the variables is positive and direct; that is, with increment of marriage age for people born in 1986, the age difference increase as well ( $\mathrm{r}=0.278$; sig=0.002).

The correlation between couples' age difference and the people of 1976 generation is -0.008 with the significant level of $0.894(\mathrm{r}=-0.008)$. So, the statistics show that there is no relation between couples' age difference and the generation of 1976. 
Table (2): Descriptive statistics respecting couples age difference for people born in generations of 1976

\begin{tabular}{|c|c|c|c|c|c|c|c|}
\hline \multicolumn{8}{|c|}{ and 1986} \\
\hline Generation & $\begin{array}{c}\text { Age } \\
\text { Group } \\
\text { (ranging } \\
\text { from 15- } \\
19 \text { ) }\end{array}$ & $\begin{array}{c}\text { Age } \\
\text { Group } \\
\text { (ranging } \\
\text { from 20- } \\
24 \text { ) } \\
\end{array}$ & $\begin{array}{c}\text { Age } \\
\text { Group } \\
\text { (ranging } \\
\text { from 25- } \\
29 \text { ) }\end{array}$ & $\begin{array}{c}\text { Age } \\
\text { Group } \\
\text { (ranging } \\
\text { from 30- } \\
\text { 34) }\end{array}$ & $\begin{array}{c}\text { Age } \\
\text { Group } \\
\text { (ranging } \\
\text { from 34- } \\
\text { 39) }\end{array}$ & $\begin{array}{c}\text { Age } \\
\text { Group } \\
\text { (ranging } \\
\text { from 40- } \\
14 \text { ) }\end{array}$ & Total \\
\hline $\begin{array}{c}\text { Generation of } \\
1986 \\
\end{array}$ & 1 & 2.6 & 3.1 & - & - & - & 2.96 \\
\hline $\begin{array}{c}\text { Generation of } \\
1976\end{array}$ & - & - & - & 2.97 & 3.02 & 2.95 & 2.98 \\
\hline
\end{tabular}

The results show that the whole couples' age difference for people born in 1986 equals 2.96 and the most mean is related to age groups ranging from 25-29 and the least mean is for couples' age difference in age groups ranging from 15-19.

The whole couples' age difference for people born in 1976 equals 2.98 and the most mean is with age groups ranging from 35-9 and the age difference mean for people in age group of 30-34 equal 2.97 and for people in age group of 40-44 this equals 2.9843 .

Fitting model for factors clarifying couples' age difference for generation of 1976

Regression analysis regression on clarifying factors show that among the independent variables transferred to the final regression model, all of the models entered the regression analysis. Couples' age difference for people born in 1976 is only influenced by couples' education and masculinity variables.

Table (3): Regression Model

\begin{tabular}{|r|r|r|r|r|r|}
\hline \multirow{2}{*}{ Model } & \multicolumn{4}{|c|}{ Change Statistics } \\
\cline { 2 - 7 } & R Square Change & F Change & df1 & df2 & Sig. F Change \\
\hline 1 & 0.202 & 2.398 & 6 & 57 & 0.039 \\
\hline
\end{tabular}

Table (4): The statistics related to the independent variables entered the model

\begin{tabular}{|l|l|l|l|l|l|}
\hline \multirow{2}{*}{ The Variable } & \multicolumn{2}{|l|}{$\begin{array}{l}\text { Non-Standardized } \\
\text { Coefficients }\end{array}$} & $\begin{array}{l}\text { Standardized } \\
\text { Coefficients }\end{array}$ & T & Significance \\
\cline { 2 - 5 } & B & Std.B & Beta & & \\
\hline The Fixed Amount & 2.018 & 4.89 & - & 4.128 & 0.000 \\
\hline Economic & -.053 & 0.051 & -0.143 & -1.039 & 0.303 \\
\hline Social & 0.010 & 0.006 & 0.090 & 1.686 & 0.093 \\
\hline Education & 0.077 & 0.034 & 0.115 & 2.277 & 0.023 \\
\hline Masculinity & 0.044 & 0.018 & 0.129 & 2.421 & 0.016 \\
\hline Age Difference & -0.131 & 0.071 & -0.096 & -1.849 & 0.065 \\
\hline
\end{tabular}

As it can be inferred from the above table in this model, the depended variable is age difference and the independent variables are masculinity, sociocultural factors as well as the education and marriage age. In this table, the regression is both and non-standardized; the standardized one in 
that the coefficient is considered and the non-standardized is one without considering coefficient. The first regression analysis with the fixed regression line is presented as follow:

Difference $=$ economic factor $(2.018-.053)$, social factor $(+0.10)$, education $(0.077)$, marriage age (-.133), masculinity (.044).

And in a non-standard status without considering the fixed regression line, it is as follow:

Age difference $=$ economic factors $(+.90 .143)$, sociocultural factors $(.090)+$ masculinity $(+.129)$ , education (115), marriage age (-.096).

As it can be inferred, significance level holds the variables of education and masculinity, respectively with amounts of .023 and .016 and the sociocultural and education variables constitute the amounts of .093 and .065 , respectively in that the test error is .05 . Therefore, one can say that the depended variable of age difference is influenced by independent variables of education, masculinity, sociocultural and marriage age.

Fitting model for factors clarifying couples' age difference for generation of 1986

The regression analysis for factors clarifying age difference for people born in 1986 show that among all of the independent variables taken to the final regression model analysis, all of which entered the analysis model. Couples' age difference for people born in 1986 only is influenced by the variables of education, marriage ageand as well as age difference.

Table (5): Regression model summary

\begin{tabular}{|r|r|r|r|r|r|}
\hline \multirow{2}{*}{ Model } & \multicolumn{4}{|c|}{ Change Statistics } \\
\cline { 2 - 7 } & R Square Change & F Change & df1 & df2 & Sig. F Change \\
\hline 1 & 0.319 & 11.136 & 5 & 119 & 0.000 \\
\hline
\end{tabular}

Table (6): The statistics related to the independent variables entered directly to the analysis model

\begin{tabular}{|l|l|l|l|l|l|}
\hline \multirow{2}{*}{ The Variable } & \multicolumn{2}{|l|}{$\begin{array}{l}\text { Non-Standardized } \\
\text { Coefficients }\end{array}$} & $\begin{array}{l}\text { Standardized } \\
\text { Coefficients }\end{array}$ & \multirow{2}{*}{ S } & Significance \\
\cline { 2 - 4 } & $\mathrm{B}$ & Std.B & Beta & & \\
\hline The Fixed Amount & 2.256 & 03.15 & - & 7.157 & 0.000 \\
\hline Economic & -.028 & 0.043 & -0.218 & -0.662 & 0.521 \\
\hline Social & 0.007 & 0.004 & -0.151 & -1.844 & 0.068 \\
\hline Education & 0.052 & 0.022 & 0.184 & 2.334 & 0.021 \\
\hline Masculinity & -.013 & 0.013 & -0.083 & -0.969 & 0.335 \\
\hline Marriage age & 0.229 & 0.050 & 0.381 & 4.569 & 0.000 \\
\hline Age Difference & .060 & .031 & .151 & 1.916 & .058 \\
\hline
\end{tabular}

In this model, the dependent variable is the generation of 1986 and the independent variables are masculinity, sociocultural factors, education, marriage age and age difference. The standardized regression line, considering the fixed coefficients, andthe non-standardized ones, without considering the fixed coefficients are calculated as follow:

The generation of $1986=$ age difference $(+. / 60)$, masculinity $(-.013)$, education +.052$)$, social factors (-.007), economic factors (2.256-.028), marriage age (.229) 
And in a non-standardized status without considering the fixed coefficient of regression is as follow:

The generation of $1986=$ age difference $(.151)$, marriage age (.381), masculinity (.083) , education (184), social factors (151), economic factors (.218)

As it can be inferred, the significance level for the variables of education and social factors are .021 and .068 , respectively and the variables of marriage age and age difference are .000 and .058 , respectively which are less than test error, that is .05. Therefore, the depended variable of the generation of 1986 is influenced by independent variables of education, sociocultural factors, marriage age and age difference.

Fitting model for factors clarifying couples' age difference for generation of 1976

The regression analysis for factors clarifying age difference and for people born in generation of 1976 show that from independent variables entered the regression analysis, all of them entered the analysis. Couples' age difference for people born in generation of 1976 is only influenced by the variables of education, marriage age and age difference.

Table (7) Regression model summary

\begin{tabular}{|r|r|r|r|r|r|}
\hline \multirow{2}{*}{ Model } & \multicolumn{4}{|c|}{ Change Statistics } \\
\cline { 2 - 7 } & R Square Change & F Change & df1 & df2 & Sig. F Change \\
\hline 1 & 0.041 & 2.278 & 5 & 264 & 0.047 \\
\hline
\end{tabular}

Table (8): Statistics related to the independent variables entered the analysis

\begin{tabular}{|l|l|l|l|l|l|}
\hline \multirow{2}{*}{ The Variable } & \multicolumn{2}{|l|}{$\begin{array}{l}\text { Non-Standardized } \\
\text { Coefficients }\end{array}$} & $\begin{array}{l}\text { Standardized } \\
\text { Coefficients }\end{array}$ & \multirow{2}{*}{ Significance } \\
\cline { 2 - 5 } & $\mathrm{B}$ & Std.B & Beta & & \\
\hline The Fixed Amount & 1.901 & .337 & - & 5.633 & 0.000 \\
\hline Economic & -.028 & 0.043 & -0.218 & ---- & 0.1 \\
\hline Social & 0.010 & 0.004 & 0.148 & 2.374 & 0.018 \\
\hline Education & 0.053 & 0.026 & -0.127 & -2.019 & 0.045 \\
\hline Masculinity & -.027 & 0.013 & -0.129 & -1.992 & 0.047 \\
\hline Marriage age & 0.048 & 0.057 & 0.054 & .836 & 0.404 \\
\hline Age Difference & .015 & .042 & .024 & .362 & .717 \\
\hline
\end{tabular}

Considering the fixed coefficient and non-standard, that is one without the fixed coefficient, the first status, the fixed regression line is as follow:

Generation of $1976=$ age difference $(+.015)$, marriage age $(+.48)$, masculinity $(-.027)$, education (-.053), social factors (-.010), economic factors (1.901-.028)

And in a non-standardized form as well as not considering regression fixed line coefficient, the following figures are presented:

The generation of $1976=$ age difference $(+.24)$, marriage age $(=.054)$, masculinity $(-.129)$, education $(-.127)$, social factors $(+148)$, social factors $(+.148)$, economic factors $(-.218)$. 
As it can be inferred, the significance level of the variables of education, sociocultural factors and masculinity are $.045, .018$ and .047 , respectively in that they are less than test error, which is .05 . Therefore, the depended variable of the generation of 1976 is influenced by the variables of education, sociocultural factors and masculinity.

\section{Conclusion}

Marriage is one of the social traditions known as a real social happening at all settings and times. The present study investigates the factors affecting couples' age differences between two generations of 1976 and 1986. Human beings are capable of choosing and one of the choices they have during their life time is one related to the spouse in that has a lot of effect on prosperity and misery for his life and family. But in some areas, the reactions are inactive and based on non-structuralism and different economic and social factors can make these age differences. The amount of reaching a desired spouse through affecting the both genders time of marriage can be useful in increment or reduction of these differences. In masculine structures, the age difference is higher (in favor of males). Also, the lower economic and cultural statuses are matched with the increment of age. It seems that renewing and development have a big part in changes related to the couples' age difference. Increased size of civilization, females' higher education degrees and their economical elaborations mostly reflexes reduction of gender inequalities and the increment of their reinforcement. Females position (employment, education and autonomy in earning) is correlated with age difference declining. In contrary, in traditional context of rural areas where females are mostly deprived from educational, economic and social achievement, marriage in early ages causes age difference. In a traditional community, males begin their matrimony in their fathers houses but in this era, the new couples would rather live in an independent house detached form their fathers houses, therefore, they face problem finding a new house. Strong dowry, lack of a suitable job and the matter of not affording the marriage, postpone their marriage. As mentioned above, civilization causes diffusion of new cultures such as individualism and tendency to progress and hereby, marriage at older ages for males. Marriage at older age for males, due to economic reasons, such as unemployment, and the social ones like individualism, cause couples' age difference. Couples' age difference can cause social and population consequence. Fertilizing as one of the changing factors of population can be influenced by couples' age difference. In addition, their age difference effect on factors like marital satisfaction and family relation sustainability. Increased time of loneliness (homelessness at the time of getting old) after husband's passing being simultaneous with hope among women can be effected by couples' age difference. Both traditionalism and modernity may affect couples age difference. According to the insights related to the subject matter, such as renewing, gender quality and factors like increment of education, civilization and industrialization are related to couples' age difference change. In city of Kamyaran, the rural dwellers age difference was higher in comparison to the urban ones. Considering this that according to the results from the statistics of Iran, the couples age difference decreases as the marriage age increases; the reason for this difference is both rural and urban areas is due to younger ages of marriage among girls dwelling in rural areas in comparison to those who live in cities. Since the marriage age mean for rural dwelling females is 22.04 comparing their counterparts in urban areas with amount of 22.94 , it is indicated that the more traditional structure of rural areas in comparison to the urban ones causes the higher amount of age difference among couples because of the insight of having the females socialized in one hand and lower amount of education and literacy in other hand, 
indicating the less renewed context of rural areas than the urban ones. The age difference among educated females (graduates) is less than their husbands in rural areas and also in urban areas; educated females (with higher education) have less age differences comparing their husbands. The couples' age difference for educated males living in urban areas show they have less age difference in comparison to males without literacy but in contrary, for males living in rural areas, their age difference is higher in comparison to those males without enough literacy. There can be seen more age difference among employed females in urban areas in comparison to the unemployed ones. The age difference for females' housekeepers is more than others. The age difference for self-employed males is more than those who are not self-employed and this is also true for self-employed males in rural areas. In $80 \%$ of the marriages taking place in urban areas, males are older than their spouses. Having the same age can be seen for 12 percent of marriages and for 6.5 percent of marriages, females are older than males. Having the same age for couples is true for $9 \%$ of marriages in rural areas and for like $6.5 \%$ of marriages in urban areas, females are older than their husbands. The age difference mean for both males in rural and urban areas equal 5.22 and 5.23, respectively and this mean for females living in both rural and urban areas equal 4.26 and 3.13, respectively. The results of this survey briefly show that there is a significant relation between age difference and variables of economic factors, sociocultural factors, marriage age, education, masculinity, generation of 1976 and generation of 1986.

\section{References}

[1] Aminzade F., Demographics of Tehran, human and social sciences Faculty, the university of Sepahian of Iranian Revolutionary(1978).

[2] Michale Asociology of family and marriage, translated by Ardalan, Farangis; human and social faculty of Tehran University, Tehran., (1997).

[3] DorodiAhi N., Lack of balance toward gender relativities for marriage ages, Demographics, 41, Tehran(2002).

[4] Zanjani H., Demographics analysis, the publication of humane science study and research center (Smat publications), Tehran(1997).

[5] Srokhani B., An introduction on the sociology of family, Soroush publication, Tehran(1991).

[6] Segalen M.,Historic sociology of family, translated by Eliasi, Hamid, Markaz publication, Tehran(1991).

[7] Abbasi S \& Khani S., Marriage patterns, ethnicity and religion: case study on married females in the city of Qorwe, Iranian Demographics Association4(3)(2008)36.

[8] Kazemipour S., Marriage age change in Iran and population factors affecting it, females' surveys Tehran2(3)(2004).

[9] Mahmoudian H \&Rahwarzgar F ., The social and population factors affecting couples' age difference in province of Ardabil, the magazine for sociocultural council of females, strategic studies4(50)(2010). 
[10] Mahmoudian H., Analyzing the amount and factors affecting couples' age difference, the letter by Demographics association1(1)(2006)127-140.

[11] Mahmoudian H., The increment of marriage age, investigating supporting factors, the social science letter(24)(2004)27-53.

[12] Iranian statistic., The sample of individual file, $20 \%$ for cnsus, 2006(2010). 